\title{
Characteristics of heavy metals's exposure from playground flooring
}

\author{
Yoon A Cho, Woo Il Kim», Sun Kyoung Shin, Young Yeul Kang, Min Sun Kim, \\ Seong Kyoung Jeong, Jin Mo Yeon, Na Jin and Ji Young Lee \\ Resource Recirculation Research Division, National Institute of Environmental Research \\ Environmental Research Complex Kyungseo-dong, Seo-gu, Incheon 404-708, Korea \\ (Received August 7, 2012; Revised October 30, 2012; Accepted November 27, 2012)

\section{놀이터 바닥재로부터 용출되는 중금속 노출 특성 국립환경과학원 자원순환연구과}

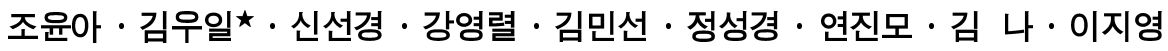

(2012. 8. 7. 접수, 2012. 10. 30. 수정, 2012. 11. 27. 승인)

\begin{abstract}
The increasing use of recycling products results in the need for assessing the risk to human health. In this study heavy metals's contents of playground flooring were compared with rubber powder which is row material. And it is reviewed characteristics of heavy metals's exposure from absorption of skin, checking amount of dermal uptake for each heavy metal. Despite its high content, $\mathrm{Zn}$ had a very low migration rate with 0.1 $\mathrm{mg} / \mathrm{cm}^{2}$. This indicates that $\mathrm{Zn}$ is not easily released by surface contact. However, the contents of $\mathrm{Fe}$ and $\mathrm{Al}$ in flooring were 12 times higher than that of $\mathrm{Zn}$ and $\mathrm{Fe}$, and $\mathrm{Al}$ showed migration rate 5 times higher than that of $\mathrm{Zn}$. This implies that $\mathrm{Fe}$ and $\mathrm{Al}$ were derived from pigment in flooring. The measurement of dermal exposure to heavy metals at 6 playgrounds found higher level of exposure in Ba than in other heavy metals. It is assumed that despite high content of $\mathrm{Zn}, \mathrm{Ba}$ had a higher exposure rate because five times as much $\mathrm{Ba}$ as $\mathrm{Zn}$ was darmal absorptionactor $\left(\mathrm{AF}_{\text {darmal }}\right)$.

요 약: 재활용 제품의 사용이 증가함에 따라 이에 대한 위해성 평가가 필요한 실정이다. 본 연구에서는 재활용 제품 중 재활용 고무분말을 이용한 놀이터용 바닥재와 해당 고무분말의 중금속 함량을 비교하였 다. 또한 각각의 물질이 경피로 전이되는 양을 확인하여 피부에 흡수되는 중금속 노출 특성을 살펴보았 다. 아연의 경우 함량이 높은데 반해 전이량이 $0.1 \mathrm{mg} / \mathrm{cm}^{2}$ 으로 매우 낮았는데 이는 아연은 표면 접촉으 로는 잘 묻어나지 않는다는 것을 나타낸다. 그러나 철과 알루미늄의 경우, 함량이 바닥재에서 12 배 높 게 나타났고, 전이량이 아연보다 약 5 배 높게 나타났다. 이것은 철과 알루미늄이 바닥재에 사용된 안료 에서 기인했다는 것을 말한다. 놀이터 6 개소를 대상으로 피부 흡수에 의한 중금속 노출량을 산정한 결 과, $\mathrm{Ba}$ 의 경우 타 중금속에 비하여 비교적 높게 산정되었다. $\mathrm{Zn}$ 의 함량이 높음에도 불구하고 $\mathrm{Ba}$ 의 노출 량이 더 높은 것은 $\mathrm{Ba}$ 의 피부흡수율이 $\mathrm{Zn}$ 에 비해 약 5 배 높기 때문인 것으로 판단된다.
\end{abstract}

Key words: recycling, assessing, exposure, playground flooring, rubber powder

Corresponding author

Phone : +82-(0)32-560-7507 Fax : +82-(0)32-568-1656

E-mail : woolr@korea.kr 


\section{1. 서 론}

현재 매우 다양한 재생원료로 재활용제품이 생산되 고 있는데 폐합성수지 및 폐타이어가 중간원료로 사 용되는 제품으로는 도로에 사용되는 고무블럭, 어린이 놀이터, 운동장에 사용되는 제품으로는 인도에 사용되 는 고무매트 및 인조잔디, 고무통, 정화조 등이 있다. 이러한 다양한 재생원료를 사용한 제품의 생산은 자 원순환의 효과로 자원고갈을 늦추고, 폐기물 처리량을 줄여 환경오염을 저감하는 효과도 있지만, 재활용 제 품 사용 시 유해물질로 인체 및 환경노출의 우려가 제기되고 있다. 국내에서는 교육과학기술부와 환경부 에서 고무분말 인조잔디와 놀이터 바닥재에 대해 연 구된 사례가 있으나, ${ }^{1}$ 노출량을 산정하여 위해성 평가 하는 단계까지 진행된 사례는 없다. 그러나 식약청 및 $\mathrm{ATSDR}$ 의 물질 정보에 의하면 피부에 의해 중금속이 흡수되기도 하며, 그 정도는 물질마다 다르기 때문에 물질 각각의 위해성 평가가 필요하다. 이에 본 연구에 서는 천시료를 이용하여 피부접촉시 전이량을 측정(in vitro)하고 Health Canada의 각 중금속 별 피부흡수율 을 사용하여 노출량을 산정하여 피부를 통해 인체로 유입되는 중금속 노출 특성을 살펴보고자 한다.

\section{2. 연구 및 방법}

\section{1. 실험 재료}

실험에 사용된 놀이터용 바닥재는 어린이 놀이터 바닥 시공 시 널리 사용되는 정사각형의 패드형태의 바닥재와 압축하여 패드를 만들기 전에 고무분말을 재료로 하였다. 바닥재는 인천시 소재 놀이터 6 곳을 대상으로 하여 시료채취 하였으며, 고무분말은 9 개사 16 개 제품을 시료채취하였다.

\section{2. 시료 채취}

연구에서 사용된 고무분말 및 바닥재는 각 제조업 체에서 구입하였으며, 바닥재의 경우 액체질소로 급속 냉각하여 잘게 분쇄하였다. 중금속 전이량 측정을 위 한 경피노출 시료는 미국 소비자제품안전위원회 (CPSC Staff analysis and assessment of synthetic Turf "Grass Blades")에서 고안한 장치 ${ }^{2}$ 의 기본틀을 바탕으 로 제작한 장치 $\left(1.3 \mathrm{~kg}\right.$ Disk, $323 \mathrm{~cm}^{2}$ sampling surface area)에 Ghost wipe (ASTM E-1792)를 장착하여 CPSC Staff의 wipe sampling 방법에 따라 바닥재 표면 시료 를 채취하였다. 시료채취에 사용된 장치의 규격은

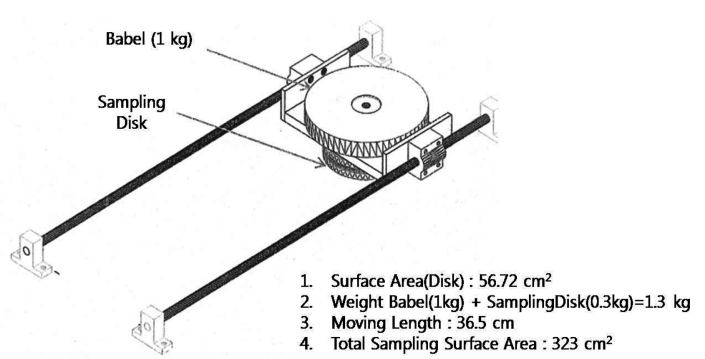

Fig. 1. Sampling equipment (CPSC staff).

Fig. 1과 같다.

\section{3. 분석 방법}

\subsection{1. 중금속 함량}

바닥재 내의 중금속 함량은 KS M 6956 재활용 고 무 분말의 유해물질 측정방법에 의해 분석하였다. ${ }^{4}$ 잘 게 분쇄된 시료 $0.2 \mathrm{~g}$ 을 달아 PTFE 용기에 넣고, 7 $\mathrm{mL} \mathrm{HNO}_{3}, 1.5 \mathrm{~mL} 50 \% \mathrm{HBF}_{4}, 1.5 \mathrm{~mL} \mathrm{H} \mathrm{H}_{2}, 1 \mathrm{~mL}$ 증류수를 가한 후, PTFE 용기를 밀폐하고 마이크로 분해 장치를 사용하여 분해하였다. 용기를 상온으로 냉각시킨 후 개봉하여 $25 \mathrm{~mL}$ 플라스크에 옮기고, 증

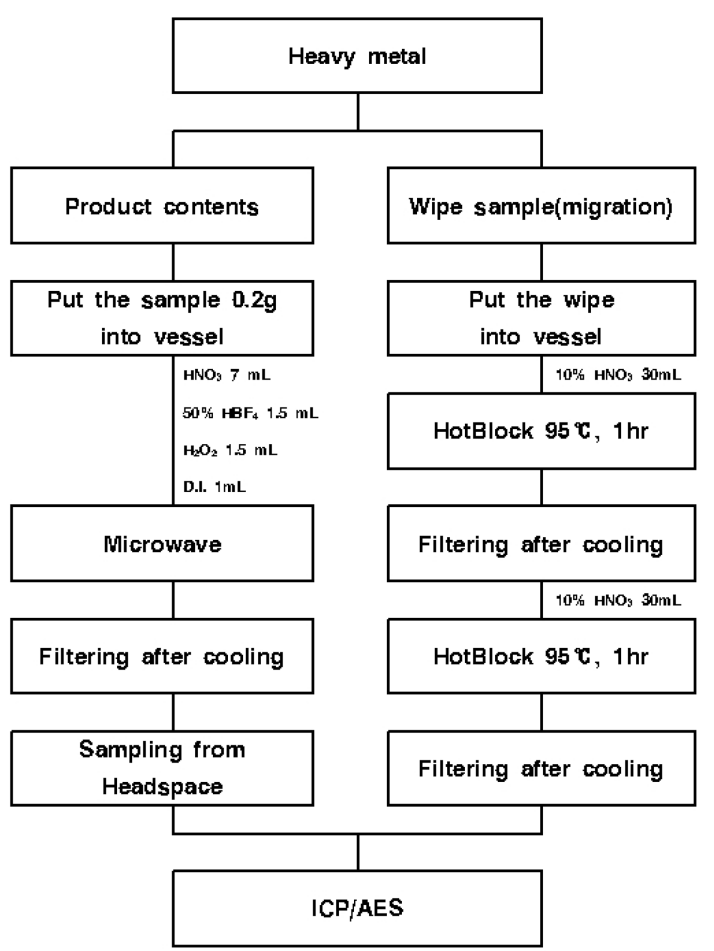

Fig. 2. Heavy metals analysis method. 
Table 1. ICP-OES heavy metals analysis condition

\begin{tabular}{ll}
\hline \hline & ICP-OES condition \\
\hline Items & Conditions \\
Model & HORIBA JOBIN YVON US/ULTIMA 2 \\
Forward power & $1200 \mathrm{~W}$ \\
Plasma gas flow & $15 \mathrm{~L} / \mathrm{min}$ \\
Auxiliary flow & $0.5 \mathrm{~L} / \mathrm{min}$ \\
Nebulizer & Glass Concentric type $0.8 \mathrm{~L} / \mathrm{min}$ \\
Sheath gas flow & $1.5 \mathrm{~L} / \mathrm{min}$ \\
Pump rate & $20 \mathrm{rpm}$ \\
\hline
\end{tabular}

류수로 눈금까지 희석한 후 이를 시험용액으로 한다 (Fig. 2). 제조된 시험용액은 ICP-OES (Inductively Coupled Plasma-Optical Emission Spectrometer)로 정 량한다. 분석에 사용된 ICP-OES는 HORIBAJOBIN YVON, Ultima2이며, 분석조건은 Table 1과 같다.

\subsection{2. 경피 전이량}

경피 전이량은 SW-846 method 3051 and 3052를 변형한 US $\mathrm{EPA}$ 의 정도보증 프로젝트 계획 2단계에 의해 분석하였다. ${ }^{5} 10 \% \mathrm{HNO}_{3} 30 \mathrm{~mL}$ 를 wipe가 들어 있는 용기에 투입하고 95 Hotblock에서 1 시간 가열 한 후, 5 분동안 식히고 $100 \mathrm{~mL}$ 플라스크에 액을 부 은 후 천시료(wipe)를 짜낸다. 깔대기와 플라스크를 증류수로 린스하고 위 과정을 반복한 후, $10 \% \mathrm{HNO}_{3}$ $20 \mathrm{~mL}$ 로 한번 더 반복 후 $100 \mathrm{~mL}$ 로 하여 이를 시험 용액으로 한다(Fig. 2). 제조된 시험용액은 ICP-OES로 정량한다. 분석에 사용된 ICP-AES는 HORIBAJOBIN YVON, Ultima2 이며, 분석조건은 Table 1과 같다.

\section{3. 결과 및 고찰}

\section{1. 고무분말과 바닥재 내 중금속 함량 비교}

고무분말 내 중금속 함량은 $\mathrm{Zn} 18,416 \mathrm{mg} / \mathrm{kg}, \mathrm{Cr}$ $6.8 \mathrm{mg} / \mathrm{kg}$, Ba $23 \mathrm{mg} / \mathrm{kg}, \mathrm{Pb} 25 \mathrm{mg} / \mathrm{kg}$, Mn $9.3 \mathrm{mg} /$ $\mathrm{kg}, \mathrm{Cu} 82 \mathrm{mg} / \mathrm{kg}$ 으로 나타났으며, 바닥재에서는 $\mathrm{Zn}$ $16,243 \mathrm{mg} / \mathrm{kg}$, Cr $4 \mathrm{mg} / \mathrm{kg}$, Ba $60 \mathrm{mg} / \mathrm{kg}, \mathrm{Pb} 15 \mathrm{mg} /$ $\mathrm{kg}, \mathrm{Mn} 10 \mathrm{mg} / \mathrm{kg}, \mathrm{Cu} 110 \mathrm{mg} / \mathrm{kgs}$ 으로 분석되었다. 이들 두 시료는 $\mathrm{Fe}$ 와 $\mathrm{Al}$ 을 제외하고 전반적으로 비슷 한 양상을 보였다. $\mathrm{Fe}$ 의 경우, 고무분말에서 $707 \mathrm{mg} /$ $\mathrm{kg}$ 이고 바닥재에서 $8,895 \mathrm{mg} / \mathrm{kg}$ 로 약 12.6 배 정도 높 게 나타났으며, $\mathrm{Al}$ 의 경 우, 고무분말에서 $780 \mathrm{mg} / \mathrm{kg}$ 이었고 바닥재에서는 $8,674 \mathrm{mg} / \mathrm{kg}$ 으로 약 11.1 배 높 은 수치로 나타났다(Fig. 3). 한편 본 연구에서 분석한

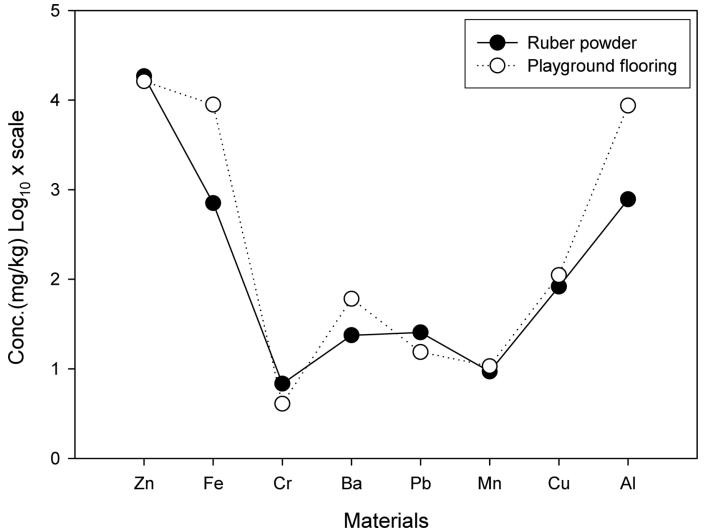

Fig. 3. Playground flooring/Ruber powder contents (mg/kg).

고무분말의 함량결과는 B. Bocca의 연구에서 ${ }^{6}$ 나타난 Zn 10,229 mg/kg, Cr $6.2 \mathrm{mg} / \mathrm{kg}$, Ba $22 \mathrm{mg} / \mathrm{kg}, \mathrm{Pb} 22$ $\mathrm{mg} / \mathrm{kg}, \mathrm{Fe} 305 \mathrm{mg} / \mathrm{kg}, \mathrm{Al} 755 \mathrm{mg} / \mathrm{kg}$ 등과 비슷한 경 향으로 나타났으나 바닥재의 수치와는 다소 차이를 보이고 있다. 이것은 $\operatorname{Lim}$ 의 연구에 따른 해석과 같이 바닥재 제조 시 들어가는 염료나 접착제로 인하여 일 부 중금속 수치가 높아질 수 있으며, 어떤 종류의 염 료를 사용하였는지에 따라 중금속 수치가 달라질 수 있는 것으로 판단된다.

\section{2. 바닥재 함량과 전이량 관계}

바닥재 함량과 경피 전이량을 살펴본 결과, $\mathrm{Zn}$ 을 제외하고 비슷한 양상을 나타내었다. $\mathrm{Zn}$ 의 경우 다른 중금속에 비해 함량이 매우 높은데 비해 전이량은 0.1 $\mathrm{mg} / \mathrm{cm}^{2}$ 수준으로 매우 낮게 나타났다. 이러한 현상은 $\mathrm{Zn}$ 이 다른 중금속에 비해 바닥재로부터 쉽게 묻어나 지 않기 때문인 것으로 판단된다. 한편 함량값이 고무 분말보다 바닥재에서 약 12 배 높았던 $\mathrm{Fe}$ 와 $\mathrm{Al}$ 은 $\mathrm{Zn}$ 에 비해 함량 대비 전이량이 높게 나타났다(Fig. 4). 이것은 $\mathrm{Fe}$ 와 $\mathrm{Al}$ 이 바닥재 표면에서 묻어날 수 있는 염료에서 기인한 것으로 보여진다. 기존 연구에 따르 면 다양한 색을 부여하기 위해 다양한 색상의 유기안 료 뿐 아니라 열 안정성 등을 보완하기 위해 일부 무 기안료를 첨가할 수 있으며, 착색안료 중 색상별로 다 른 무기물질로 이루어져 있다고 보고하였다. ${ }^{1}$

\section{3. 피부 흡수에 의한 중금속 노출량 평가}

놀이터 6개소를 대상으로 피부 흡수에 의한 중금속 노출량을 위해성평가 가이드북 ${ }^{9}$ 을 참고하여 산정하였 다. 피부 접촉 면적과 체중은 한국인인체치수조사 


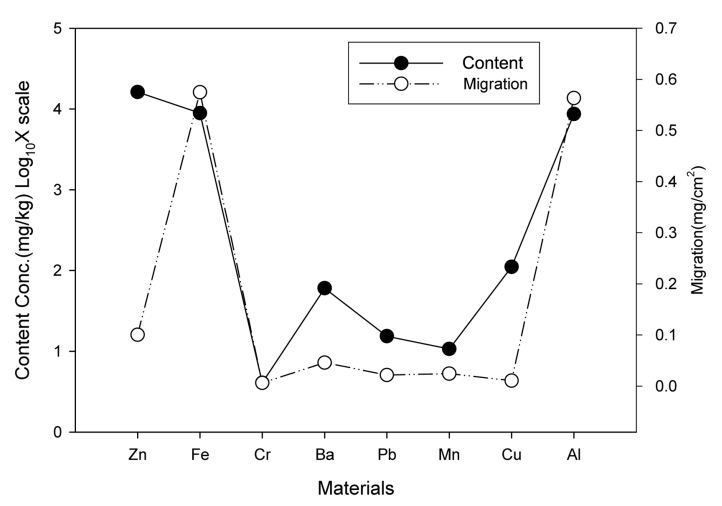

Fig. 4. Relation of playground flooring contents and migration through the skin.

web-site의 자료를 활용 하였으며, 6-7세 아동의 양손 면적과 체중을 이용하였다. 접촉시간은 기존 재활용 제품의 노출량 평가 보고서를 참조하였으며, 피부흡수 율은 캐나다 오염 지역 위해성 평가보고서에서 참조 하여 사용하였다. ${ }^{7,8}$ 사용된 물질 별 피부흡수율은 바 닥재와 같이 평평한 물질 표면에서 피부로 흡수되는 흡수율 값이 존재하지 않아, 토양에 함유된 유해물질 이 피부로 흡수되는 값을 이용하였다. $\mathrm{Fe}, \mathrm{Mn}, \mathrm{Al}$ 의 경우 제시된 피부흡수율 자료가 없어 노출량을 산정
하지 않았다. 피부 흡수에 의한 중금속 노출량을 평가 하기위해 식 (1)과 같은 노출 알고리즘을 이용하였다.

$$
\mathrm{ADD}=\frac{\mathrm{M} \times \mathrm{S} \times \mathrm{ET} \times \mathrm{ABs}}{\mathrm{BW}}
$$

여기서 $\mathrm{ADD}$ 는 일일노출량 $(\mathrm{mg} / \mathrm{kg} / \mathrm{day}), \mathrm{M}$ 은 인체전이 량 $\left(\mathrm{mg} / \mathrm{cm}^{2} / \mathrm{min}\right), \mathrm{S}$ 는 피부접촉면적 $\left(\mathrm{cm}^{2}\right), \mathrm{ET}$ 는 접촉시 간(min/day), $\mathrm{ABs}$ 는 피부흡수율, $\mathrm{BW}$ 는 체중 $(\mathrm{kg})$ 을 나타 낸다. ${ }^{9,11}$

놀이터 6개소에 대한 경피 노출량은 식 (1)에 의하 여 산정되었으며 결과는 Table 2와 같다. $\mathrm{Zn}$ 은 $0.0013 \sim 0.0529 \mathrm{mg} / \mathrm{kg} / \mathrm{day}, \mathrm{Pb} \quad 0.0001 \sim 0.0008 \mathrm{mg} / \mathrm{kg} /$ day, $\mathrm{Cu} 0.0067 \sim 0.0229 \mathrm{mg} / \mathrm{kg} / \mathrm{day}, \mathrm{Ba} 0.0073 \sim 0.0255$ $\mathrm{mg} / \mathrm{kg} / \mathrm{day}$ 수준으로 산정되었다(Table 3). 함량결과에 서 $\mathrm{Zn}$ 의 농도값이 $\mathrm{Ba}$ 에 비해 압도적으로 높은데 반해 노출량에서 비교적 낮은 수준을 나타낸 것은 $\mathrm{Zn}$ 은 $\mathrm{Ba}$ 보다 더 쉽게 묻어나지 않는다는 것을 말하고 피부흡 수율이 $\mathrm{Ba}$ 의 $1 / 5$ 수준으로 더 낮기 때문인 것으로 판 단된다.

$\mathrm{BK}$ 2-2 시료에서는 전이량이 불검출로 나타나 노출 량이 산정되지 않았다. 이는 전이시료 채취 시점이 강 우 직후였기 때문에 표면이 씻겨나가 중금속이 묻어 나지 않은 것으로 판단된다.

Table 2. Using exposure factor

\begin{tabular}{|c|c|c|c|c|c|}
\hline Pathway & Factor & & Value & Unit & Reference \\
\hline \multirow{8}{*}{$\begin{array}{c}\text { Skin } \\
\text { absorption }\end{array}$} & \multicolumn{2}{|c|}{ Skin contact area } & 163.48 & $\mathrm{~cm}^{2}$ & Sizekorea \\
\hline & \multicolumn{2}{|l|}{ Contact period } & 0.5 & $\min /$ day & NIER, $2010^{7}$ \\
\hline & \multirow{5}{*}{$\begin{array}{c}\mathrm{AF}_{\text {dermal }} \\
\text { (Dermal absorption factor) }\end{array}$} & Zinc & 0.02 & \multirow{5}{*}{-} & \multirow{5}{*}{ Health Canada, 2004} \\
\hline & & Chromium & 0.04 & & \\
\hline & & Barium & 0.1 & & \\
\hline & & Lead & 0.006 & & \\
\hline & & Aluminium & 0.1 & & \\
\hline & \multicolumn{2}{|c|}{ Body weight (age 6-7) } & 24.09 & $\mathrm{~kg}$ & Sizekorea $^{10}$ \\
\hline
\end{tabular}

Table 3. Result of dermal exposure amount from playground flooring

(Unit : mg/kg/day)

\begin{tabular}{|c|c|c|c|c|c|c|c|c|}
\hline \multirow{2}{*}{ Code } & \multicolumn{8}{|c|}{ Heavy metals } \\
\hline & $\mathrm{Zn}$ & $\mathrm{Fe}$ & $\mathrm{Cr}$ & $\mathrm{Ba}$ & $\mathrm{Pb}$ & $\mathrm{Mn}$ & $\mathrm{Cu}$ & $\mathrm{Al}$ \\
\hline FK 2-4 & 0.0138 & $* a)$ & - & 0.0073 & - & $*$ & - & $*$ \\
\hline BK 2-2 & $-^{b)}$ & $*$ & - & - & - & $*$ & - & $*$ \\
\hline EK 2-2 & 0.0323 & * & - & - & 0.0008 & $*$ & 0.0229 & * \\
\hline CK 2-2 & 0.0013 & $*$ & - & - & - & $*$ & 0.0067 & $*$ \\
\hline SK 2-4 & 0.0151 & $*$ & - & 0.0255 & 0.0007 & $*$ & 0.0089 & $*$ \\
\hline MK 2-2 & 0.0529 & $*$ & - & 0.0134 & 0.0001 & $*$ & - & $*$ \\
\hline
\end{tabular}

${ }^{\mathrm{a})}$ Exception for exposure amount of $\mathrm{Fe}, \mathrm{Mn}, \mathrm{Al}$ because of no data in $\mathrm{AF}_{\text {dermal }}{ }^{8}$

b) Not detected

Vol. 25, No. 6, 2012 


\section{4. 결 론}

재활용 원료를 이용한 제품 생산 시 유해물질로 인 한 인체 및 환경노출의 우려가 제기됨에 따라 원재료 인 고무분말과 바닥재의 중금속 함량을 살펴보았다. 또한 각각의 물질이 경피로 전이되는 양을 확인하여 피부에 흡수되는 중금속 노출 특성을 살펴본 결과는 다음과 같다.

1. 고무분말과 놀이터 바닥재의 중금속 함량은 비슷 한 양상을 보였으나, $\mathrm{Fe}$ 와 $\mathrm{Al}$ 의 경우 바닥재에서 $\mathrm{Fe}$ $8,895 \mathrm{mg} / \mathrm{kg}, \mathrm{Al} 8,674 \mathrm{mg} / \mathrm{kg}$ 으로 고무분말보다 약 12 배 높은 수치로 나타났다. 이는 바닥재 제조 시 들 어가는 염료나 접착제에 의해 일부 중금속 수치가 높 아질 수 있으며, 어떤 종류의 염료를 사용하였는지에 따라 중금속 수치가 달라질 수 있다.

2. 바닥재 함량과 경피 전이량을 살펴본 결과, $\mathrm{Zn}$ 의 경우 함량이 높은데 반해 전이량이 낮은 수준으로 나 타났다. 이러한 현상은 $\mathrm{Zn}$ 이 다른 중금속에 비해 바 닥재로부터 쉽게 묻어나지 않는다는 것을 말해준다. 또한 $\mathrm{Fe}$ 과 $\mathrm{Al}$ 의 바닥재 전이량이 $\mathrm{Zn}$ 보다 약 5 배 높은 것으로 보아 바닥재에 사용된 안료에서 기인한 것으 로 보여진다.

3. 놀이터 6 개소를 대상으로 피부 흡수에 의한 중 금속 노출량을 산정한 결과, 함량결과에서 $\mathrm{Zn}$ 의 농도 값이 $\mathrm{Ba}$ 에 비해 압도적으로 높은데 반해 노출량에서 낮은 수준을 나타낸 것은 $\mathrm{Zn}$ 은 $\mathrm{Ba}$ 보다 더 쉽게 묻어 나지 않는다는 것을 말하고 피부흡수율이 $\mathrm{Ba}$ 의 $1 / 5$ 수준으로 더 낮기 때문인 것으로 판단된다.

\section{참고문헌}

1. Y. W. Lim, 'Hazardous materials survey and risk assessment of synthetic turf field and rubber powder(I)', Ministry of Environment, 2009.

2. CPSC Staff, 'analysis and assessment of synthetic Turf "Grass Blades", CPSC, 2008.

3. ASTM Standard E1792-96E, 'Standard Specification for Wipe Sampling Materials for Lead in Surface Dust', ASTM International, West Conshohocken, PA, www.astm.org.

4. Korean Agency for Technology and standards No. KS M 6956:2010, 'Test method for estimating the toxicity of recycled rubber powder', 2010.

5. U.S. Environmental Protection Agency Air Pollution Prevention and Control Division, 'Evaluation of the Effectiveness of Coatings in Reducing Dislodgeable Arsenic, Chromium, and Copper from CCA Treated Wood', QAPP Revision 6, North Carolina 27709, 2003.

6. B. Bocca, G. Forte, F. Petrucci, S. Costantini and P. Izzo, Sci. Total Environ., 407(7), 2183-2190 (2009).

7. D. Jung, S. O. Han, K. P. Nam, 'Study on risk and management of waste timber from railroad', National institute environmental research, 2010.

8. Health Canada, 'Federal contaminated site risk assessment in canada Part I : Guidance on human health preliminary quantitative risk assessment', Ottawa, 2004.

9. National institute environmental research, 'risk assessment guidebook', 2011.

10. Korean agency for technology and standards, http:// www.sizekorea.kats.go.kr, Assessed 4 June 2010.

11. Ajou university, http://www.kefh.or.kr, Assessed 4 December, 2008. 